\title{
Endoscopic Treatment of Metabolic Syndrome
}

\author{
Eduardo Guimarães Hourneaux de Moura, Ivan Roberto Bonotto Orso, \\ Bruno da Costa Martins and Guilherme Sauniti Lopes
}

Additional information is available at the end of the chapter

http://dx.doi.org/10.5772/45989

\section{Introduction}

For a long time, obesity has been known as a risk factor for cardiovascular disease, which is one of the main causes of death in developed countries. The prevalence of obesity (defined as having a body mass index [BMI] of $30 \mathrm{~kg} / \mathrm{m} 2$ or more) is increasing in both developing and developed countries. A 5-kg/m2 increase in body mass index (BMI) increases the risk of cardiac complications by $29 \%$ [1]. This risk is due to the coexistence of other factors associated with obesity, such as hypertension, dyslipidemia, nonalcoholic fatty liver disease and abnormalities in glycemic metabolism. Resistances to insulin and lipid abnormalities are commonly found among obese patients with type 2 diabetes mellitus (T2DM) and are strongly related to an increase of cardiovascular risk. Resistance to insulin and consequent compensatory hyperinsulinemia significantly increase the risk of death due to cardiovascular diseases [2-5].

To identify the patients with metabolic syndrome, insulin resistance, and greater cardiovascular risk, there are criteria, established by the Adult Treatment Panel III (NCEP ATP III), that include the presence of three of more of the following: central obesity (abdominal circumference above $102 \mathrm{~cm}$ in men and $88 \mathrm{~cm}$ in women), increased triglycerides (greater than or equal to $150 \mathrm{mg} / \mathrm{dl}$ ) or use of a lipid-lowering agent, reduced HDL cholesterol (lower than $40 \mathrm{mg} / \mathrm{dl}$ among men and lower than 50mg/dl among women) or use of a lipid lowering agent, hypertension (systolic arterial pressure greater than or equal to $130 \mathrm{mmHg}$ or diastolic pressure greater than or equal to $90 \mathrm{mmHg}$ ) or use of an antihypertensive agent, andglucose levels greater than or equal to $100 \mathrm{mg} / \mathrm{dl}$ or use of an oral hypoglycemic agent and/or insulin [6].

Despite this, recent studies propose that the use of the TG/HDL (Triglicerides/High Density Lipoprotein) ratio may be a more practical way to estimate insulin resistance. It is believed that the greater the ratio, the greater the insulin resistance of the patient. This ratio provides an estimate of the sensitivity to insulin and is as accurate as the criteria for the metabolic 
syndrome defined by the ATP III, the concentration of plasma insulin when fasting, or other estimates that measure the amount of glucose and the plasma concentration of insulin in order to evaluate its action [5, 7 -9]. Some studies suggest that the increase of the TG/HDL ratio may better predict the risk of cardiovascular diseases than do conventional risk factors such as hypertension, tobacco use, and physical activity [10].

To control the obesity and insulin resistance the initial steps are lifestyle changes aimed at controlling diet and increasing activity with the goal of reducing body weight, followed by the addition of orally active pharmacologic agents and insulin to the treatment regimen.

However, dietary modification and pharmaceutical therapy offer limited potential for sustained weight loss, effective in fewer than $5 \%$ of cases [2]. In a meta-analysis of pharmacotherapy for obesity, the percentages of patients achieving $5 \%$ and $10 \%$ weight loss thresholds by using anti obesity drugs were $54 \%$ and $18 \%$, respectively, but a lack of adherence to treatment limited the efficacy and effectiveness [11].

Weight loss surgery, in contrast, has been shown to effect a more durable response . In addition, it can induce reversal of obesity-associated comorbidities [2,12].

Of interest is the observation that obese patients with diabetes who undergo certain gastric bypass procedures demonstrate improvement in glycemia, often within days of surgery and before significant weight loss. The exact mechanism responsible for this dramatic effect of surgical procedures for obesity on diabetes improvement is not fully understood; however, the surgical rearrangement of the anatomy of the gastrointestinal (GI) tract changes the location where partially digested nutrients first contact the intestine, suggesting that correction of dysfunctional homeostatic mechanisms may contribute to the glycemic improvement. Whether it is a pure effect of weight reduction or bypass of the hormonally active foregut has a primary effect remains a controversy. Hypothesis includes weight reduction, decreased caloric intake, and bypass of the hormonally active foregut [12-14].

However, weight loss surgery is associated with complications such as anastomotic leak and ulcer presenting a mortality rate estimates range between 0.1 and $2.0 \%$ [2].

Endoscopic weight loss therapies may provide some of the benefits of weight loss surgery while being reversible, with a lower risk profile, and being available to patients who do not qualify for surgery or are poor candidates for surgery. Those endoscopic solutions for weight loss are also applicable as metabolic procedures to address comorbidities as type 2 diabetes, dyslipidemia and nonalcoholic fatty liver disease.

\section{Physiopathology of metabolic improvement after metabolic surgery}

Several studies have shown a significant diabetes improvement in obese patients who undergo certain gastric bypass procedures. The improvement of glycemia is observed, often within days of surgery and before significant weight loss. The mechanism responsible for this improvement is not fully understood; however, the surgical rearrangement of the 
anatomy of the gastrointestinal tract may contribute to the glycemic improvement. If the glicemic improvement is a pure effect of weight reduction or bypass of the hormonally active foregut has a primary effect remains a controversy. Hypothesis to explain those effects includes weight reduction, decreased caloric intake, and bypass of the hormonally active.foregut. [12-14]

Two hypothesis have been proposed to explain the effect of duodenal jejunal bypass on type 2 diabetes. The "hindgut hypothesis" holds that diabetes control results from the expedited delivery of nutrient chyme to the distal intestine, enhancing a physiologic signal that improves glucose metabolism. A potential candidate mediator of this effect is glucagon-like peptide 1 (GLP-1). This incretin hormone is secreted by L cells of the distal bowel in response to intestinal nutrients. It stimulates insulin secretion and exerts proliferative and antiapoptotic effects on pancreatic beta cells.16 If proven true, the hindgut hypothesis would spur further research on methods to enhance signaling by GLP-1 (or other distal gut peptides) to treat type 2 diabetes [14-16]. An alternative hypothesis is that the effect of selected bariatric operations on diabetes depends on exclusion of the duodenum and proximal jejunum from the transit of nutrients, possibly preventing secretion of a putative signal that promotes insulin resistance and type 2 diabetes ("foregut hypothesis"). Although no obvious candidate molecules can be identified with current knowledge, if proven true, this hypothesis might open new avenues in the search for the cause and cures of diabetes $[14,17,18]$.

Several reports supported that the duodeno jejunal exclusion (foregut hypothesis) owes to a direct effect of the bypass of the hormonally active foregut. Rubino and Marescaux showed in their study in animal model that bypassing a short segment of proximal intestine directly ameliorates type 2 diabetes, independently of effects on food intake, body weight, malabsorption, or nutrient delivery to the hindgut [14].

However,in previous studies, it was observed that a strict calorie restriction, as performed in the first weeks after bariatric surgery, could bring itself to a normalization of plasma glucose and insulin levels before body weight decrease $[19,20]$.

Wei-Jei Lee in a study comparing the band (restrictive) with the gastric bypass (duodeno jejunal bypass), with a longer follow-up, showed that the gastric banding group had a similar improvement of insulin resistance to the bypass group while similar weight reduction was achieved. The gastric banding group had similar result at postoperative 6 months compared to the gastric bypass group at the first postoperative month. Also, 3 months to 1 year and 6 months to 2 years were compatible. Suggesting that for a longterm effect of resolution of insulin resistance, sustained weight reduction plays the key mechanism [12].

Improvement in the glycemic control, insulin resistance and metabolic syndrome after bariatric surgery is regulated by a complex mechanism and still there is no certainty whether it is a pure effect of calorie restriction and weight reduction or it is caused by the bypass of the hormonally active foregut . 


\section{Metabolic improvements with the intragastric baloon}

The intragastric baloon is a spherical silicone elastomer balloon that is resistant to degradation by gastric acid for approximately 6 months. It can be placed endoscopicallyand filled with 400 to $700 \mathrm{ml}$ of saline and methylene blue dye, which changes the color of the urine in the event of balloon rupture.

Balloon insertion and removal are performed under conscious sedation or general anesthesia. Before the insertion, an upper gastrointestinal endoscopy is performed to detect possible contraindications to the procedure. The baloon placement device is inserted through the mouth into the stomach. Then the balloon is positioned in the fundus under endoscopic control, and inflated by injecting saline mixed with $10-\mathrm{ml}$ methylene blue into the catheter. Finally, once the desired volume has been injected, the balloon is released by a short pull on the catheter. The baloon should be removed after a maximum of 6 months because beyond this period, the risk of spontaneous balloon deflation significantly increases.

A meta-analysis by Imaz et al. [21] of 15 studies comprising 3698 patients estimated $14.7 \mathrm{~kg}$ weight loss, $32.1 \%$ excess weight loss (EWL), and $5.7 \mathrm{~kg} / \mathrm{m} 2$ decrease in BMI after 6 months.

In a review including 22 studies with a total of 4371 patients implanted with the intragastric baloon, demonstrated a mean weight loss of $17.8 \mathrm{Kg}$, with extremes of the means of 4.9 $28.5 \mathrm{~kg}$ and higher absolute values observed in higher BMI categories. [22].

A prospective study, evaluating the effect of the baloon on weight, insulin resistance, and liver steatosis in obese patients showed that $76 \%$ of the patients had a BMI decrease of 3.5 $\mathrm{Kg} / \mathrm{m}^{2}$ or more. The mean (SD) weight loss with respect to baseline values was $16.4(8.2) \mathrm{kg}$ with a corresponding mean (SD) BMI reduction of $6.4(3.2) \mathrm{kg} / \mathrm{m} 2$. The absolute percentage of participants with glycemia levels of $100 \mathrm{mg} / \mathrm{dL}$ or higher decreased from $50 \%$ to $12 \%$, those with triglyceridemia $150 \mathrm{mg} / \mathrm{dL}$ or higher from $58 \%$ to $19 \%$, and those with abnormal ALT level from $38 \%$ to $7 \%$ [23].

Two studies (one randomized, one uncontrolled) totaling 143 patients have reported that, one year after BIB removal, patients had regained $41 \%$ and $28 \%$ (mean values, respectively) of the absolute weight loss observed at BIB removal [24,25]. Another study following 88 patients for a median of 22 month after baloon withdrawal, observed that (50\%) regained some weight, 34 (39\%) maintained their weight, and the remaining $10(11 \%)$ continued to lose weight [23].

It is also important to consider that $20-40 \%$ of patients fail to achieve a significant weight loss (often defined as $\geq 10 \%$ baseline weight or $\geq 25 \%$ excess weight). Such failures may be related to the request of early baloon removal by patients who present a digestive or psychological intolerance to the baloon, to the early vanishing of anticipated effects on hunger and early satiety, or to patient's adaptation of food intake [23].

In conclusion, the BIB strategy may be an alternative to current management of obesity focused on lifestyle changes, drug therapy, and treating associated metabolic complications. 
Although the baloon has not yet proved to be a convincing means of primary long term weight loss, it holds some promise for improving co-morbidities and quality of life in nonmorbidly obese patients or those who are unwilling to undergo bariatric surgery. New perspectives are also beginning to show its potential value in specific patient groups especially, for example, those preparing for surgery.

\section{Metabolic improvements with duodeno jejunal bypass liner}

A totally different concept, that of mimicking principles of bariatric surgery, has recently been applied in the development of the endoscopic duodenal-jejunal bypass liner. In addition to early satiety and delayed gastric emptying, the intraluminal sleeve aims at creating a duodenojejunal exclusion.

The DJBL is a sterilized, single-use endoscopic device, which is minimally invasive and employed under radioscopic control. It is composed of a nitinol anchoring with tiny lateral barbs for fixation and an impermeable plastic conduit made of a fluorine polymer $62 \mathrm{~cm}$ in length, which impedes contact of the chyme with bile-pancreatic secretions prior to the proximal segments of the jejunum. FIGURE 1

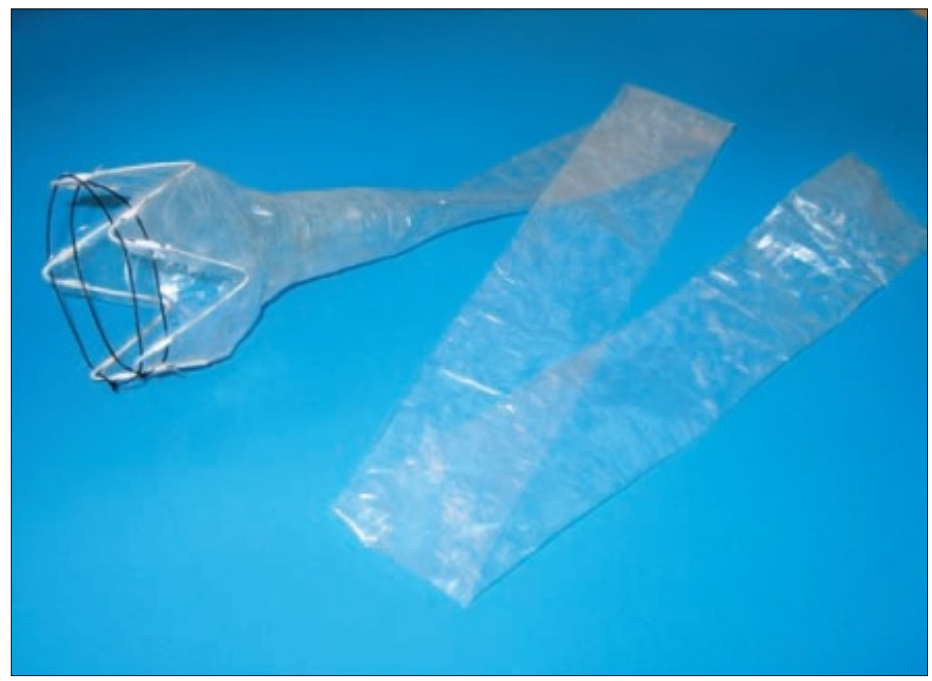

Figure 1. Impermeable plastic conduit and anchor system.

Endoscopic implantation is performed under general anesthesia. The device is introduced over a guidewire that has been previously positioned in the duodenal bulb with endoscopic assistance. The plastic conduit is stretched to overlay the duodenum and the proximal region of the jejunum. After the correct positioning of the plastic conduit, the anchoring system is freed, setting the device in the duodenal bulb. The infusion of a contrast agent is performed to verify the correct positioning of the prosthesis and the absence of obstructions within the plastic conduit. FIGURE 2 


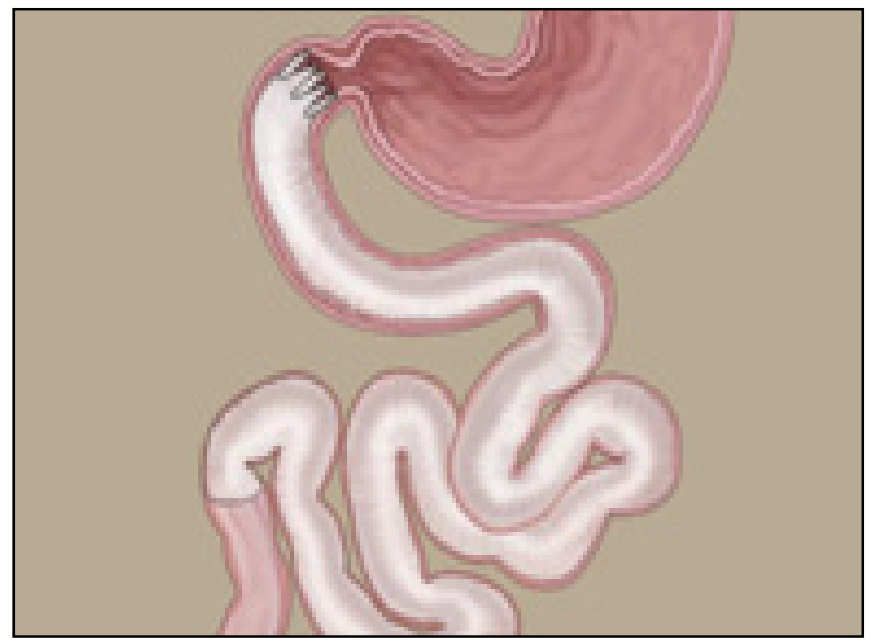

Figure 2. Implanted DJBL.

Previously studies with obese patients that used the duodenojejunal bypass liner (DJBL) demonstrated a significant weight loss. In addition, an improvement in the control of T2DM was observed, which was statistically greater than that of the group treated with a lowcalorie diet [26-33].

Our group in the Gastrointestinal Endoscopy Unit of the University of São Paulo School of Medicine performed a prospective study to evaluates the effectiveness of this method over the control of hyperlipidemia, improvement of insulin resistance, metabolic syndrome, and in the potential benefit in the reduction of cardiovascular risk [34].

The inclusion criteria of the study were ages between 18 and 65 years, BMI $\geq 35 \mathrm{~kg} / \mathrm{m} 2$, T2DM with or without other comorbidities, and a triglyceride/high-density lipoprotein cholesterol ratio (TG/HDL) ratio greater than or equal to 3.5, indicating insulin resistance.

To identify patients with resistance to insulin and metabolic syndrome, TG/HDL ratio has proved to be an excellent practical indicator. This ratio estimates the resistance to insulin and is as accurate in terms of the clinical criteria for metabolic syndrome as specified by the Adult Treatment Panel III [6], the measure of the fasting concentration of plasma insulin,or other estimates that measure glycemia and the plasma concentration of insulin in order to identify individuals with insulin resistance $[5,7,8]$. In addition, the TG/HDL ratio has proved to be an independent factor that was correlated with the risk of cardiovascular events [5].

A low TG/HDL ratio indicates large particles and a lower atherogenic potential of LDL cholesterol, while a high TG/ HDL ratio indicates a large population of small, dense, and pro-atherogenic particles of LDL cholesterol [7]. The lipid disorder consisting of the increase of plasma triglycerides and the reduction of HDL cholesterol, known as atherogenic dyslipidemia, is directly associated with insulin resistance and is also an independent risk factor for cardiovascular diseases [3-5, 7]. 
Eighty-one patients were selected for implantation of the device. Of these, 78 successfully received the implant and three were not given the implant due to anatomic factors (short bulb). Among the 78 patients, one was excluded from the analysis for not having performed the laboratory measures. Of the 77 remaining patients, we calculated the initial TG/ HDL ratio (at the time of the implant), identifying 54 patients $(70 \%)$ with a ratio greater than or equal to 3.5, indicating the presence of insulin resistance and metabolic syndrome. These patients were included in the study and were monitored in order to evaluate whether or not an improvement occurred in this ratio during the period in which they had the implanted device.

We compared the TG/HDL ratio at the time of the implant with the ratio obtained after 6 months to evaluate whether there was an improvement in insulin resistance. We divided the patients into two groups: those who demonstrated a ratio below 3.5 in the end of the study, considered as control of the insulin resistance, and those that did not demonstrate values lower than 3.5. In the two groups, we evaluated whether control of T2DM and weight loss occurred during this period, and we correlated the influence of the control of diabetes and weight loss with the improvement of TG/HDL. We considered a significant weight loss to be a reduction of at least $10 \%$ of initial body weight and control of T2DM as an $\mathrm{HbA} 1 \mathrm{c}$ level lower than $7 \%$. The patients who presented a reduction of $\mathrm{HbA} 1 \mathrm{c}$ levels greater than $1.5 \%$ yet did not obtain values lower than $7 \%$ were considered to have partial control over DM2.

The overall initial average of the TG/HDL ratio was 5.75 and presented a significant reduction down to 4.36 at the end of the 6 months $(p=<0.001)$, indicating an improvement of insulin resistance (Table 1). Of these patients, 23 (42.6\%) presented control of the TG/HDL ratio with values lower than 3.5 at the end of the study. This group presented a significant improvement in the ratio, which decreased from 5.15 to $2.85(\mathrm{p}<0.001)$. Thirty-one patients did not show a controlled TG/HDL ratio but rather a discrete improvement, with an initial average of 6.2 and a final of 5.47 , with no statistical difference $(p=0.1641)$.

\begin{tabular}{lcccc}
\hline & Patients N & $\begin{array}{l}\text { Initial average } \\
\text { TG/HDL ratio }\end{array}$ & $\begin{array}{c}\text { Final average } \\
\text { TG/HDL ratio }\end{array}$ & p \\
\hline $\begin{array}{l}\text { Baseline non } \\
\text { controlled TG/HDL }\end{array}$ & 54 & 5,75 & 4,36 & 0,001 \\
$\begin{array}{l}\text { Controlled TG/HDL } \\
\text { at the end }\end{array}$ & 23 & 5,15 & 2,85 & $<0,001$ \\
$\begin{array}{l}\text { Not controlled } \\
\text { TG/HDL at the end }\end{array}$ & 31 & 6,2 & 5,47 & 0,1641 \\
\hline
\end{tabular}

Table 1. Improvement on TG/HDL ratio.

In order to identify the differences between the group that presented an improvement in the ratio and the group that did not, we evaluated the control of T2DM (HbA1c improvement) and the success of weight loss (reduction $>10 \%$ of initial weight).

In the evaluation of T2DM control (Table 2), we observed that all patients presented a significant improvement in the levels of $\mathrm{HbA1c}(\mathrm{p}<0.001)$. In the group that controlled the 
TG/HDL ratio, three patients already had diabetes controlled at the beginning of the study, with an initial average of $\mathrm{HbA} 1 \mathrm{c}$ of $6.4 \%$ and a final of $5.83 \%(\mathrm{p}=0.023)$. Fifteen patients did not have diabetes under control, presenting an initial average of $7.8 \%$, and then developing control of T2DM, with a final average of $6.1 \%(p<0.001)$. Five patients did not have diabetes undercontrol and obtained partial control after the intervention. These patients presented higher initial levels of $\mathrm{HbA} 1 \mathrm{c}$ than those of the group that controlled diabetes, with an initial average of $10.34 \%$, and presented a significant reduction of the final average of $8.88 \%(\mathrm{p}=0.03)$.

In the group that did not control the TG/HDL ratio, five patients already had T2DM under control, with an initial average of $6.6 \% \mathrm{mg} / \mathrm{dl}$ and a final average of $6.2 \%(\mathrm{p}=0.037)$. Fifteen patients did not have diabetes under control and were able to bring it under control with initial and final averages of $8.5 \%$ and $6.4 \%$, respectively ( $\mathrm{p}=0.001$ ). Eleven patients did not have diabetes under control and obtained partial control. These patients also presented a higher level of HbA1c than that of the patients who had controlled T2DM, with an initial average of $9.9 \%$, reaching a significant reduction at the end of the study with an average of $7.7 \%(\mathrm{p}=0.003)$, which is very close to the level required for T2DM control.

An association was not observed between the control of T2DM and an improvement in the TG/HDL ratio (Table 3).

\begin{tabular}{|c|c|c|c|c|}
\hline \multicolumn{5}{|c|}{ Diabetes improvement on TG/HDL controlled patients } \\
\hline Diabetes & Patients N & $\begin{array}{c}\text { Inial } \mathrm{HbA1c} \\
\text { average }\end{array}$ & $\begin{array}{c}\text { Final } \mathrm{HbA1c} \\
\text { average }\end{array}$ & p \\
\hline $\begin{array}{l}\text { Already controled } \\
\text { and improved }\end{array}$ & 3 & 6,4 & 5,38 & 0,023 \\
\hline $\begin{array}{l}\text { Not controled who } \\
\text { controlled }\end{array}$ & 15 & 7,8 & 6,1 & $<0,001$ \\
\hline $\begin{array}{l}\text { Not controlled with } \\
\text { partial control }\end{array}$ & 11 & 10,34 & 8,88 & 0,03 \\
\hline HbA1c Worsening & 0 & - & - & . \\
\hline \multicolumn{5}{|c|}{ Diabetes improvement on TG/HDL not controlled patients } \\
\hline Diabetes & Patients & $\begin{array}{c}\text { Inial } \mathrm{HbA1c} \\
\text { average }\end{array}$ & $\begin{array}{c}\text { Final } \mathrm{HbA1c} \\
\text { average }\end{array}$ & $\mathbf{p}$ \\
\hline $\begin{array}{l}\text { Already controled } \\
\text { and improved }\end{array}$ & 5 & 6,6 & 6,2 & 0,037 \\
\hline $\begin{array}{l}\text { Not controled who } \\
\text { controlled }\end{array}$ & 15 & 8,5 & 6,4 & 0,001 \\
\hline $\begin{array}{l}\text { Not controlled with } \\
\text { partial control }\end{array}$ & 11 & 9,9 & 7,7 & 0,003 \\
\hline HbA1c Worsening & 0 & - & - & . \\
\hline
\end{tabular}

Legend: Diabetes evolution on TG/HDL controlled and not controlled patients. Glycemic improvement was statistically significant in all groups of patients.

Table 2. Diabetes improvement. 
Diabetes Improvement - HbA1c

\begin{tabular}{cccc}
\hline $\begin{array}{c}\text { Already } \\
\text { controled and } \\
\text { improved }\end{array}$ & $\begin{array}{c}\text { Not controlled } \\
\text { who controlled }\end{array}$ & $\begin{array}{c}\text { Not controlled } \\
\text { with partial } \\
\text { control }\end{array}$ & $\begin{array}{c}\text { HbA1c } \\
\text { Worsening }\end{array}$ \\
\hline
\end{tabular}

\begin{tabular}{|c|c|c|c|c|}
\hline $\begin{array}{l}\text { TG/HDL } \\
\text { controlled } \\
(n=23)\end{array}$ & 3 & 15 & 5 & 0 \\
\hline $\begin{array}{l}\text { TG/HDL not } \\
\text { controlled } \\
(n=31)\end{array}$ & 5 & 15 & 11 & 0 \\
\hline
\end{tabular}

Legend: Relationship between improvement of diabetes and TG/HDL control. Patients improved diabetes regardless of having controlled the TG/HDL ratio (p 0,35).

Table 3. Relation between TG/HDL ratio control and $\mathrm{HbA} 1 \mathrm{C}$ control.

In relation to weight loss (Table 4), the patients lost on average $12.6 \%$ of their initial weight. Among the 23 patients who controlled their TG/HDL ratio, 19 (82.6\%) lost more than $10 \%$ of their initial weight. The average initial weight of these patients was $116.5 \mathrm{~kg}$ and the average final weight was $97 \mathrm{~kg}$, constituting an average loss of $16.7 \%$ of initial weight. Four patients did not lose more than $10 \%$ of their weight. The average initial weight of these patients was $94.4 \mathrm{~kg}$, and the average final weight was $87.47 \mathrm{~kg}$, marking an average loss of $7.4 \%$. In the group that did not control the TG/HDL ratio, 15 lost more than $10 \%$ of their initial weight $(48 \%)$, with an average initial weight of $123.9 \mathrm{~kg}$ and an average final weight of $105.7 \mathrm{~kg}$ (loss of $14.6 \%$ in initial weight). Sixteen patients did not lose more than $10 \%$ of their weight, presenting an average initial weight of $111.9 \mathrm{~kg}$ and an average final weight of $103.5 \mathrm{~kg}$, with an average loss of $7.5 \%$ in initial weight.

\begin{tabular}{|c|c|c|c|c|}
\hline \multicolumn{3}{|c|}{ Weight loss on TG/HDL controlled patients } & \multirow[b]{2}{*}{$\begin{array}{c}\text { Final average } \\
\text { weight - Kg }\end{array}$} & \multirow[b]{2}{*}{$\begin{array}{c}\text { Percentage of } \\
\text { loss }\end{array}$} \\
\hline Weight loss & $\begin{array}{l}\text { Patients N } \\
(\%)\end{array}$ & $\begin{array}{c}\text { Inicial average } \\
\text { weight - Kg }\end{array}$ & & \\
\hline $\begin{array}{l}\text { Over than } 10 \% \text { of } \\
\text { initial weight }\end{array}$ & $19(82,6)$ & 116,5 & 97 & 16,7 \\
\hline $\begin{array}{l}\text { Less than } 10 \% \text { of } \\
\text { initial weight }\end{array}$ & $4(17,4)$ & 94,4 & 87,47 & 7,4 \\
\hline \multicolumn{3}{|c|}{ Weight loss on TG/HDL not controlled patients } & & \\
\hline Weight loss & $\begin{array}{l}\text { Patients N } \\
(\%)\end{array}$ & $\begin{array}{l}\text { Inicial weight } \\
\text { average }\end{array}$ & $\begin{array}{l}\text { Final weight } \\
\text { average }\end{array}$ & $\begin{array}{l}\text { Percentage of } \\
\text { loss }\end{array}$ \\
\hline $\begin{array}{l}\text { Over than } 10 \% \text { of } \\
\text { initial weight }\end{array}$ & $15(48)$ & 123,9 & 105,7 & 14,6 \\
\hline $\begin{array}{l}\text { Less than } 10 \% \text { of } \\
\text { initial weight }\end{array}$ & $16(52)$ & 111,9 & 103,5 & 7,5 \\
\hline
\end{tabular}

Table 4. Weight loss 
Comparing the patients who lost weight with the patients who controlled their TG/HDL ratio, an association can be observed between a weight loss greater than $10 \%$ of initial weight and control of the TG/HDL ratio $(\mathrm{p}<0.01)$, with an odds ratio of 5.06 (Table 5).

\begin{tabular}{lccc} 
& \multicolumn{3}{c}{ Weight loss } \\
\cline { 2 - 4 } & $\begin{array}{c}\text { Over than } 10 \% \text { of } \\
\text { inicial weight }\end{array}$ & $\begin{array}{c}\text { Less than } 10 \% \text { of } \\
\text { inicial weight }\end{array}$ & Total \\
\hline $\begin{array}{l}\text { TG/HDL controlled - } \\
\text { N (average } \\
\text { weight loss \%) }\end{array}$ & $19(16,7)$ & $4(7,4)$ & 23 \\
$\begin{array}{l}\text { TG/HDL not controlled } \\
\text { N (average } \\
\text { weight loss \%) }\end{array}$ & $15(14,6)$ & $16(7,5)$ & 31 \\
\hline
\end{tabular}

Legend: Relationship between weight loss and TG/HDL control. Control of TG/HDL ratio is related to weight loss greater than $10 \%$ of initial weight. (p 0,01- OR 5,06).

Table 5. Relation between TG/HDL ratio control and weight loss.

Of the 54 patients included in this 6 months study, 38 have completed (26 completed 24 weeks, 12 completed 20 weeks). Among the 16 patients left, 12 had the device removed at 16 weeks, 2 at 12 weeks, and 2 had the implant for just 4 weeks. The early implant removals occurred due to migration of the device in nine patients, the observation of a free device anchor during endoscopic exam in four patients, the presence of bleeding without migration in one patient, subject request in one case, and due to the decision of the researcher in one case.

In resume, all patients implanted with the device presented a statistically significant reduction of the levels of $\mathrm{HbA1c}$, and the majority of these patients $(70.3 \%)$ presented values lower than $7 \%$ at the end of the study and were therefore considered to be controlled diabetics. In addition, all patients presented a statistically significant reduction of initial weight, with an average general loss of $12.6 \%$ of initial weight. Regarding the improvement of insulin resistance and metabolic syndrome, there was a significant reduction of the TG/HDL ratio from 5.75 to $4.36(\mathrm{p}=0.0001)$. Of these patients, $42.6 \%$ controlled their insulin resistance, presenting a TG/HDL ratio value lower than 3.5 at the end of the study.

Among the patients who controlled the TG/HDL ratio, the reduction of the ratio went from 6.8 at the beginning of the study to 2.8 at the end $(\mathrm{p}<0.001)$.

In other study conducted by our group, twenty two implanted patients were followed during a period of 1 year [13]. In the full analysis population, the mean percentage excess weight loss was $35.5 \%(\mathrm{P}<0.0001)$. The reduction in excess body weight was reflected by reductions in BMI and waist circumference of $6.7 \mathrm{~kg} / \mathrm{m} 2$ and $13.0 \mathrm{~cm}$, respectively.

The improvement in glycemic control is convincingly demonstrated by the results with a percentage of subjects with $\mathrm{HbA} 1 \mathrm{c}<7 \%$ at baseline improved from $4.5 \%$ to $73.0 \%$ at final 
study assessment. Statistically significant reductions in fasting blood glucose ( - $30.3 \pm 10.2$ $\mathrm{mg} / \mathrm{dL})$, fasting insulin ( $-7.3 \pm 2.6 \mathrm{lU} / \mathrm{mL})$, and HbA1c $(-2.1 \pm 0.3 \%)$ were observed.

Blood levels of total cholesterol, low-density lipoprotein cholesterol, and triglycerides also were significantly reduced during the study.

On this one year series, thirteen subjects completed the 52-week period, and 18 subjects completed at least 24 weeks. The mean duration of the implant period for all subjects was 41.9 \pm 3.2 weeks. The reasons for early removal of the device were migration or rotation of the device ( $\mathrm{n}=3 ; 36,36$, and 48 weeks post implantation), GI bleeding ( $\mathrm{n}=1 ; 4$ weeks post implantation), abdominal pain ( $\mathrm{n}=2 ; 21$ and 30 weeks post-implantation), and principal investigator request due to subject's non compliance with study visits ( $n=2 ; 20$ and 32 weeks post implantation). The device was removed from one subject who presented an abdominal tumor not related to the device.

Sixteen subjects had HbA1c measured 3 and/or 6 months after explantation of the DJBL. These subjects demonstrated a mean decrease in $\mathrm{HbA} 1 \mathrm{c}$ during the original 52-week study of $-2.3 \pm 0.4 \%$. Three and 6 months after removal of the device, their mean changes from baseline were $-2.3 \pm 0.3 \%(n=15)$ and $-1.7-0.7 \%(n=11)$, respectively.

The DJBL offers a new non-surgical therapeutic possibility, positioned between pharmacological drugs and the various techniques employed in bariatric surgery. This technology platform may be employed prior to bariatric surgery to help control T2DM, in order to promote weight loss and a reduction of visceral fat, lipid control, a reduction of insulin resistance, and of cardiovascular risk,minimizing the risk of per operative clinical complications, accustoming the patient to a restricted diet that will be necessary in the postoperative period and can even be used as a substitution for bariatric surgery as a less invasive technique in selected cases.

\section{Conclusion}

As the prevalence of obesity increases, less invasive methods will be needed to obtain a sustained weight loss. Some new endoscopic tools and methods are being investigated and they could be applied as first-line therapy for obesity, to control the metabolic comorbidities, to reduce the operatory risk prior bariatric and metabolic surgery and as substitution of surgery in selected cases.

The intragastric baloon and the Duodeno Jejunal Bypass Liner are tools with promising results in the endoscopic treatment of obesity. They are still subject of research with a great potential for improvement. Although outcomes from the use of the intragastric baloon and the DJBL are not comparable to those of surgery with regard to weight loss and late results, these new techniques have showed an excelent result in ameliorating health status, in the control of the metabolic syndrome as well as improving the quality of life for a well selected group of patients. 


\section{Author details}

Eduardo Guimarães Hourneaux de Moura*,

Bruno da Costa Martins, Guilherme Sauniti Lopes

Department of Gastroenterology, Gastrointestinal Endoscopy Unit,

Hospital das Clínicas - University of São Paulo School of Medicine, São Paulo, Brazil

Ivan Roberto Bonotto Orso

Department of Gastroenterology, Gastrointestinal Endoscopy Unit, Hospital das Clínicas - University of São Paulo School of Medicine. São Paulo, Brazil

Department of Surgery, School of Medicine of the Assis Gurgacz Faculty,

Gastroclínica Cascavel, Brazil

\section{References}

[1] Bogers RP, Bemelmans WJ, Hoogenveen RT, et al. Association of overweight with increased risk of coronary heart disease partly independent of blood pressure and cholesterol levels: a metaanalysis of 21 cohort studies including more than 300000 persons. Arch Intern Med. 2007;167(16):1720-8.

[2] Kumar N, Thompson CC. Endoscopic solutions for weight loss. Current Opinion in Gastroenterology 2011, 27:407-41

[3] McLaughlin T, Abbasi F, Cheal K, et al. Use of metabolic markers to identify overweight individuals who are insulin resistant. Ann Intern Med. 2003;139:802-9.

[4] Shishehbor MH, Hoogwef BJ, Lauer MS. Association of triglyceride to HDL cholesterol ratio with heart rate recovery. Diabetes Care. 2004;27(4):936-41.

[5] McLaughlin T, Reaven G, Abbasi F, et al. Is there a simple way to identify insulin resistant individuals at increased risk of cardiovascular disease? Am J Cardiol. 2005;96(3):399-404.

[6] Tong PC, Kong AP, SoWY, et al. The usefulness of the international diabetes federation and the national cholesterol education program's Adult Treatment Panel III definitions of the metabolic syndrome in predicting coronary heart disease in subjects with type 2 diabetes. Diabetes Care. 2007;30(5):1206-11.

[7] Hadaegh F, Dhalili D, Ghasemi A, et al. Triglyceride/HDLcholesterol ratio is an independent predictor for coronary heart disease in a population of Iranian men. Nutr Metab CardiovascDis. 2009;19(6):401-8.

[8] Vasques ACJ, Rosado LEFPM, Rosado GP, et al. Indicadores do perfil lipídico plasmático relacionados à resistência á insulina. Rev Assoc Méd Bras. 2009;55(3):342-6.

[9] Quizada Z, Paoli M, Zerpa Y, et al. The triglyceride/HDL cholesterol ratio as a marker of cardiovascular risk in obesechildren; association with traditional and emergent risk factors. Pediatr Diabetes. 2008;9(5):464-71.

[10] Kannel WB, Vasan RS, Keyes MJ, et al. Usefulness of the triglyceride high density lipoprotein versus the cholesterol high density lipoprotein ratio for predicting insulin

${ }^{*}$ Corresponding Author 
resistance and cardiometabolic risk (from the Framingham Offspring Cohort). Am J Cardiol. 2008;101(4):497-501.

[11] Rucker D, Padwal R, Li SK, et al. Long term pharmacotherapy for obesity and overweight: update and meta-analysis. Br Med J 2007;335: 1194-9.)

[12] Lee WJ, Lee YC, Ser KH, Chen JC, Chen SC. Improvement of Insulin Resistance After Obesity Surgery: A Comparison of Gastric Banding and Bypass Procedures Obes Surg 2008; 18:1119-1125

[13] Moura,EGH, Martins BC, Lopes GS, Orso IR, Oliveira SL, Galva o Neto MP, et al. Metabolic Improvements in Obese Type 2 Diabetes Subjects Implanted for 1 Year with an Endoscopically Deployed Duodenal-Jejunal Bypass Liner. Diabetes Technol Ther 2012;14(2). DOI: 10.1089/dia.2011.0152

[14] Rubino F, Forgione A, Cummings DE, Vix M, Gnuli D, Mingrone G et al, The Mechanism of Diabetes Control After Gastrointestinal Bypass Surgery Reveals a Role of the Proximal Small Intestine in the Pathophysiology of Type 2. Ann Surg 2006;244: 741-749

[15] Mason EE. The mechanism of surgical treatment of type 2 diabetes. Obes Surg. 2005;15:459-461.

[16] Patriti A, Facchiano E, Sanna A, et al. The enteroinsular axis and the recovery from type 2 diabetes after bariatric surgery. Obes Surg. 2004; 14:840-848.

[17] Pories WJ, Albrecht RJ. Etiology of type II diabetes mellitus: role of the foregut. World J Surg. 2001;25:527-531.

[18] Rubino F, Gagner M, Gentileschi P, et al. The early effect of the Roux-en-Y gastric bypass on hormones involved in body weight regulation and glucose metabolism. Ann Surg. 2004;240:236 -242.

[19] Kelly DE, Wing R, Buonocore C, et al. Relative effect soft calorie restriction and weight loss in non-insulin-dependent diabetes mellitus. J Clin Endocrinol Metab. 1993;77:1287-93. 21.

[20] Ash S, Reeves MM, Yeo S, et al. Effect of intensive dietetic interventions on weight and glycemic control in overweight men with type II diabetes: a randomized trial. Int J Obes. 2003;27: 797-802.)

[21] Imaz I, Martı'nez-Cervell C, Garci'a-Alvarez EE, et al. Safety and effectiveness of the intragastric balloon for obesity. A meta-analysis. Obes Surg 2008;7:841-846.

[22] Dumonceau JM. Evidence-based Review of the Bioenterics Intragastric Balloon for Weight Loss. Obes Surg (2008) 18:1611-1617

[23] Forlano R, Ippolito AM, Iacobellis A, et al. Effect of the BioEnterics intragastric balloon on weight, insulin resistance, and liver steatosis in obese patients. Gastrointest Endosc 2010; 71:927-933.

[24] Herve J, Wahlen $\mathrm{CH}$, Schaeken A, et al. What becomes of patients one year after the intragastric balloon has been removed? Obes Surg. 2005;15:864-70.

[25] Mathus-Vliegen EM, Tytgat GN. Intragastric balloon for treatment- resistant obesity: safety, tolerance, and efficacy of 1-year balloon treatment followed by a 1-year balloonfree follow-up. Gastrointest Endosc. 2005;61:19-27.

[26] Gersin KS, Keller JE, Stefanidis D, et al. Duodenal-jejunal bypass sleeve: a totally endoscopic device for the treatment of morbid obesity. Surg Innov. 2007;14(4):275-8.

[27] Schauer P, Chand B, Brethauer S. New applications for endoscopy: the emerging field of endoluminal and transgastric bariatric surgery. Surg Endosc. 2007;21:347-56. 
[28] Tarnoff M, Shikora S, Lembo A, et al. Chronic in-vivo experience with an endoscopically delivered and retrieved duodenal-jejunal bypass sleeve in a porcine model. SurG Endosc. 2008;22(4):1023-8.

[29] Tarnoff M, Shikora S, Lembo A. Acute technical feasibility of an endoscopic duodenaljejunal bypass sleeve in a porcine model: a potentially novel treatment for obesity and type 2 diabetes. Surg Endosc. 2008;22(3):772-6.

[30] Tarnoff M, Rodriguez L, Escalona A, et al. Open label, prospective, randomized controlled trial of an endoscopic duodenal-jejunal bypass sleeve versus low calorie diet for pre-operative weight loss in bariatric surgery. Surg Endosc. 2009;23(3):650-6.

[31] Rodriguez-Grunert L, Galvao Neto MP, Alamo M, et al. First human experience with endoscopically delivered and retrieved duodenal- jejunal bypass sleeve. Surg Obes Relat Dis. 2008;4(1):55-9.

[32] Rodriguez L, Reyes E, Fagalde P, et al. Pilot clinical study of an endoscopic, removable duodenal-jejunal bypass liner for the treatment of type 2 diabetes. Diabetes Technol Ther. 2009;11 (11):725-32.

[33] Schouten R, Rijs CS, Bouvy ND, et al. A multicenter, randomized efficacy study of the EndoBarrier Gastrointestinal Liner for presurgical weight loss prior to bariatric surgery. Ann Surg. 2010;251(2):236-43

[34] Moura EGH, Orso IR, Martins BC, Lopes GS, Oliveira SL, et al. Improvement of Insulin Resistance and Reduction of Cardiovascular Risk Among Obese Patients with Type 2 Diabetes with the Duodenojejunal Bypass Liner. Obes Surg (2011) 21:941-947 